Estudios Constitucionales, Año 15, No 1, 2017, pp. 373 - 404

ISSN 07180195

Centro de Estudios Constitucionales de Chile Universidad de Talca

"El Estado socialista según la legislación irregular de Carlos Dávila

(junio-septiembre de 1932)"

\title{
EL ESTADO SOCIALISTA SEGÚN LA LEGISLACIÓN IRREGULAR DE CARLOS DÁVILA (JUNIO-SEPTIEMBRE DE 1932)*
}

\author{
THE SOCIALIST STATE ACCORDING TO THE IRREGULAR \\ LEGISLATION OF CARLOS DÁVILA (JUNE-SEPTEMBER 1932)
}

\author{
Eric Eduardo Palma González** \\ Universidad de Chile \\ epalmag@derecho.uchile.cl
}

\begin{abstract}
RESUMEN: El artículo se ocupa de estudiar desde una óptica histórica-jurídica constitucional, cuestión no hecha hasta ahora, la legislación irregular dictada entre los meses de junio y septiembre de 1932, luego de la llamada República Socialista de Chile. Del análisis legislativo se desprende la visión de Estado socialista de Carlos Dávila. Las medidas que dicha legislación pretendia instaurar, permiten poner en tela de juicio la tradicional contraposición sostenida por la historiografía socialista entre el Gobierno de Carlos Dávila y dicha República. El cuestionamiento se justifica, además, al constatar las coincidencias de Marmaduque Grove, el APRA peruano y Dávila, a propósito de la política del New Deal.

ABSTRACT: The article is devoted to study from a historical and legal perspective, issue not made so far, the irregular legislation enacted between June and September 1932, after the so-called Socialist Republic of Chile. Legislative analysis Socialist vision of Carlos Davila State follows. The measures intended to introduce such legislation allow putting into question the traditional sustained opposed by socialist historiography between the government of Carlos Davila and said Republic. The question is further justified, finding the coincidences of Marmaduque Grove, the Peruvian APRA and Davila, regarding the New Deal.

PALABRAS CLAVE: Gobierno socialista 1932, Estado socialista 1932, decretos leyes 1932, Carlos Dávila. KEYWORDS: 1932 Socialist Government, Socialist State 1932, Decree Laws 1932, Carlos Davila.
\end{abstract}

\section{INTRODUCCIÓN}

El interés historiográfico y político por los 12 días de la denominada República Socialista del año 1932, la gran relevancia que se da a la misma por la historio-

\footnotetext{
* Trabajo recibido el 26 de junio de 2016 y aprobado el 26 de abril de 2017.

** Abogado. Magíster en Historia, Universidad de Chile. Suficiencia Investigadora Doctorado en Historia Universidad de Valladolid, España. Doctor en Derecho, Universidad de Valladolid, España. Profesor titular Universidad de Chile, cátedra Historia del Derecho e Historia Institucional de Chile, Facultad de Derecho, Universidad de Chile. Senador Universitario. Correo electrónico epalmag@derecho.uchile.cl.
} 
grafía socialista en relación con la historia del Partido Socialista ${ }^{1}$, ha eclipsado y desatendido ${ }^{2}$ el fenómeno político institucional y legislativo que le sobrevino y que se prolongó hasta el mes de septiembre del mismo año, cuyo protagonista principal fue Carlos Dávila.

Hay un juicio político negativo de Dávila y su Gobierno, generado sin analizar ni ponderar su labor legislativa. Dado que la investigación histórica-jurídica tiene como foco de atención el fenómeno institucional y legislativo, con este trabajo esperamos contribuir a superar este déficit y como consecuencia a cuestionar parcialmente la actual perspectiva negativa.

El proceso de investigación histórico-jurídico constitucional se centró en dar respuesta a las siguientes preguntas: ¿La producción legislativa de la República Socialista es diametralmente opuesta a la de Dávila en lo tocante al contenido normativo? ¿Se pueden reconocer elementos de continuidad entre ambas legislaturas? ¿La continuidad tiene que ver con la asignación de un nuevo rol económico al Estado? ¿Usó el Partido Socialista la normativa dictada por Dávila con posterioridad a 1933? La hipótesis con que se trabajó es que, habiendo empleado el Gobierno de Salvador Allende, para llevar adelante su programa socioeconómico, uno de los decretos leyes dictados por Carlos Dávila (el Decreto Ley No 520 de 1932), se podía presumir puntos de contacto. Lo que era contrario a la tesis dominante del quiebre entre Grove y Dávila (incluso la literatura habla de la traición de Dávila). Y que se ha visto reforzada con la errónea atribución de la autoría del decreto ley citado a la República Socialista.

La importancia de nuestro trabajo radica en que se cuestiona la tesis de la historiografía socialista según la cual no existe punto de contacto entre Carlos Dávila y el Partido Socialista chileno. Ello a pesar de que en los decretos leyes dictados en Chile luego del término de la llamada República Socialista de 1932, se usó por Carlos Dávila las voces Estado Socialista, Gobierno Socialista y Régimen de Gobierno Socialista para intentar legitimar una fórmula estatal, cuyo análisis muestra evidentes puntos de contacto con el New Deal, el Aprismo peruano y algunas ideas de Marmaduque Grove.

El artículo se divide en tres apartados. En los dos primeros se describen brevemente los sucesos políticos del Chile de 1932 y la actividad legislativa de

\footnotetext{
1 Véase por todos, Jobet (1971) y Dinamarca (1987).

2 Hace excepción a esta tendencia nacional el conjunto de trabajos del académico polaco Ryszard Stemplowski, de los que daremos cuenta en este artículo.
} 
la llamada República Socialista. Seguidamente se da noticia de la actividad de Carlos Dávila y se comparan ambas legislaturas, para efectos de determinar el alcance de las medidas propuestas desde el punto de vista de la transformación de la realidad socioeconómica e institucional. Luego se describe con cierto detalle las regulaciones con las que Carlos Dávila vinculó las expresiones Estado Socialista, Gobierno Socialista y Régimen de Gobierno Socialista. Finalmente, se conecta dicha normativa con el programa del partido APRA y, a propósito de las ideas de Grove, con el New Deal norteamericano.

Todo lo cual nos permite concluir que las voces referidas implicaron medidas o acciones que la literatura historiográfica chilena y extranjera consideran propias de un socialismo de Estado. Medidas y acciones que no resultan ajenas, ni contradictorias, con el accionar concreto del Partido Socialista. Debilitando de este modo la propuesta historiográfica del socialismo criollo, según la cual Carlos Dávila carece de relevancia para entender el devenir del socialismo nacional.

La fuente fundamental de nuestra investigación son los decretos leyes de la etapa junio a septiembre de $1932^{3}$. Del estudio de la totalidad de los decretos leyes dictados después de la República Socialista de 1932, surgió el hallazgo que Dávila justificó la normativa jurídica contenida en ellos recurriendo a las voces Estado Socialista, Gobierno Socialista y Régimen de Gobierno Socialista.

Analizando la legislación irregular de 1932, daremos cuenta que tuvo lugar en dicha época la promulgación de un conjunto relevante de normativa que puso en tela de juicio al Estado pasivo del liberalismo clásico. Implicó también la instalación de las voces Estado Socialista, Gobierno Socialista y Régimen de Gobierno Socialista, para describir fenómenos enteramente nuevos: el accionar de una institucionalidad pública estatal y la intervención estatal del mercado, en favor de los sectores más desposeídos del país, así como de pequeños productores y comerciantes. Correspondió a Carlos Dávila un papel relevante en esta actividad político-legislativa que puede entenderse como compatible con otras acciones impulsadas en Chile, en Estados Unidos y en Perú, y que fueron valoradas po-

3 Tomados de Recopilación de los decretos-leyes dictados en 1932 por orden numérico, con indices por número, Ministerios y materias/Contraloría General de la República, Secretaría General, Editorial Nascimento, 1933. A fin de no tener que reiterar la fuente, todos los decretos leyes que se citan en este artículo han sido tomados de esta Recopilación. 
sitivamente en su momento por Marmaduque Grove y más tarde por el Partido Socialista chileno ${ }^{4}$.

\section{LOS SUCESOS POLÍTICOS}

El inicio de la década de 1930 resultó particularmente complejo para la sociedad chilena como consecuencia de los negativos efectos de la gran depresión de 1929, que terminaron tumbando a Carlos Ibáñez del Campo. Como consecuencia de la incapacidad de los gobernantes para resolver los gravísimos problemas socioeconómicos generados por la debacle de la economía mundial, se abrió un período de crisis política. El 4 de junio de 1932 se destituyó al Presidente de la República, Esteban Montero, y se constituyó una Junta de Gobierno integrada por Arturo Puga, Carlos Dávila y Eugenio Matte, quienes preocupados por pan, techo y abrigo para el pueblo ${ }^{5}$, declararon fundada la República Socialista ${ }^{6}$.

Por Decreto del Ministerio del Interior número 1728 se dispuso:

"La Excma. Junta de Gobierno decretó con esta fecha lo que sigue: Los subscriptos nos constituimos en una Junta de Gobierno que tendrá a su cargo la dirección de los negocios públicos.

Esta Junta, en el ejercicio de su misión, mantendrá el Poder Judicial y respetará la Constitución y las leyes de la República en cuanto sean compatibles con el nuevo orden de cosas. Tómese razón, comuníquese, publíquese e insértese en el Boletín de Leyes y Decretos del Gobierno-Arturo Puga-Carlos Dávila-Eugenio Matte H.”.

La República duró sólo 12 días. Dávila, habiéndose retirado del Gobierno el 14 de junio, encabezó el 16 de junio el movimiento cívico militar que le

4 ARRATE y RojAS en su historia del socialismo chileno (2003) no hacen mención alguna a este proceso ni a esta normativa.

5 En la proclama "La Junta de Gobierno al País", de 5 de junio de 1932, se señala expresamente: "Mientras se organiza la economía en forma de que el Gobierno pueda cumplir su obligación de asegurar trabajo para todos, se adoptarán las medidas necesarias para dar al pueblo alimento, vestuario y vivienda" (el documento en Devés y Díaz (1987), pp. 189-191, p. 190.

Estas ideas no pasaron desapercibidas. Jobet dice al respecto: "Matte y Grove incorporaron a las masas al rodaje administrativo del Estado... Su consigna: alimentar, vestir y domiciliar al pueblo, resumía su programa y encauzaba las explosiones rebeldes de las masas laboriosas hacia la implantación del socialismo", JOBEт (1971), p. 32.

6 Jobet (1987), p. 69. 
puso fin. El éxito del alzamiento implicó la relegación de Grove y Matte a la Isla de Pascua.

Carlos Dávila (1887-1955) estudió a partir de 1911 en la Facultad de Leyes de la Universidad de Chile, militó en la juventud del Partido Radical. Interrumpió sus estudios de Derecho para dedicarse al periodismo (trabajó en El Mercurio y en el diario La Nación como secretario de redacción). Fue designado embajador en Estados Unidos por Carlos Ibáñez del Campo, ejerciendo el cargo entre 1927 y 1931. Terminó en este país sus estudios de Derecho, obteniendo el doctorado en la Universidad de Columbia en 1928 y en 1929 una especialización en Derecho Constitucional en la Universidad de Southtern en California 7 .

La nueva Junta comenzó a gobernar a partir del día 17 de junio. La integraron Nolasco Cárdenas Díaz (diputado demócrata), el senador radical Alberto Cabero y Carlos Dávila. Se instauró un régimen con escasa base social, que no tuvo capacidad para enfrentar la crisis a pesar de que recurrió al estado de sitio $^{8}$.

Dávila disolvió la Junta a principios del mes de julio y se declaró Presidente Provisional de la República9 . También gobernó recurriendo a la declaración de estado de sitio y la ley marcial ${ }^{10}$.

Las protestas de civiles y militares contra su Gobierno lo obligaron a renunciar. Le sucedió el coronel Bartolomé Blanche, quien tuvo que abandonar el poder obligado por las guarniciones de Antofagasta y de Concepción. Asumió, entonces, el Presidente de la Corte Suprema Abraham Oyanedel, quien convocó a elecciones presidenciales para el día 30 de octubre. Resultó electo Arturo Alessandri Palma, quien asumió la presidencia de la República el 24 de diciembre de 1932.

\footnotetext{
7 Regresó a Estados Unidos en 1933, para ocupar la cátedra de Derecho Internacional en la Universidad de Carolina del Norte. En 1940 colaboró con el establecimiento de la Comisión Interamericana para el Desarrollo. Obtuvo en 1942 el premio de la prensa norteamericana, Maria Moors Cabot. En 1946 se integró como miembro al Consejo Económico y Social de las Naciones Unidas. En 1952, llamado por Ibáñez, regresó a Chile para dirigir el Diario La Nación. En los años de 1954-1955 ejerció el cargo de Presidente de la OEA. Falleció en 1955 mientras ejercía la presidencia del organismo. (Carlos Dávila Espinoza, Memoria Chilena, <http:/www.memoriachilena.cl/602/w3-article-31403.html> y <http://www.oas.org/children/ secgen /Secret Gen Eng/davilaSpan.html> -consulta marzo 2016-).

8 Para este tema y la relación con los partidos puede verse, con provecho, el trabajo de SimONETTI (1995).

9 AYLWIN-BASCUÑÁn et al. (1992), p. 111; consideran a todas estas juntas como parte de la República Socialista, afirmando "comprendió gobiernos de signos diferentes".

10 Decreto Ley No 51, Decreto Ley No 244 de junio y julio de 1932 y Decreto Ley No 452 de 20 de agosto de 1932.

Para estos sucesos, véase Loveman y LiRa (2000), pp. 10-20.
} 


\section{De la República Socialista (del 4 al 16 de junio de 1932)}

El programa económico de la República Socialista condenaba expresamente al sistema económico liberal en que se desenvolvía el país, y cuyo único efecto práctico era, no obstante el discurso a favor de la libertad (de la que supuestamente emanaba la justicia y la equidad), la explotación y la generación de desigualdades sociales: "En realidad, tales principios no son sino la careta doctrinaria que ha sido utilizada para entregar al capitalismo extranjero el control de nuestra eficiencia productora y el de nuestra capacidad consumidora"11. Calificó la presencia del capital extranjero como una grave amenaza para el país:

"El monopolio del comercio por las casas extranjeras las ha llevado a ser los árbitros de los precios de nuestro mercado, arma que han sabido esgrimir para esquilmar a los productores y esclavizar a los consumidores.

La entrega a empresas extranjeras de toda nuestra industria pesada y de gran parte de los servicios públicos ha puesto en sus manos el control de los salarios, el mercado de los brazos y el valor de la moneda.

Nuestra clase privilegiada ha vivido embriagada por los lujos y la molicie que le proporcionaba el capitalismo extranjero a cambio de nuestras riquezas naturales y de la miseria del pueblo"12.

La Junta criticó la promoción de la competencia y el supuesto carácter científico de las ideas liberales. Un verdadero gobierno, señalaba, debe atender a la desigualdad y proporcionar protección al débil frente al abuso del poderoso: "La verdadera doctrina gubernativa debe consistir en dar mayores posibilidades materiales a los más débiles y en limitar la ambición de los más fuertes. El Gobierno debe impedir que el hambre, la desnudez y el desamparo hagan su presa en el pueblo... Todos los derechos individuales pueden ser conculcados y todos los privilegios abolidos, como en el caso de guerra, cuando así lo exige la salvación del pueblo"13.

Matte declaró a la prensa en 1932:

"El carácter esencial de nuestra Revolución, es el carácter económico. Hasta hoy los gobiernos democráticos habían afirmado su revolucionarismo palabrero en los paliativos de las leyes sociales, sin tocar en ningún momento el engranaje económico

11 Joвet (1987), p. 71.

12 Idem.

13 Jовет (1987), pp. 72 у 74. 
que constituye la sociedad burguesa. Muy bien sabían manejar el habilidoso juego demagógico de las leyes sociales, porque bien sabían que, sin tocar la estructura económica, esas leyes, por la fuerza de los hechos, se iban lentamente desvirtuando. Así tenemos que, de la Ley de la Vivienda, promulgada el año de 1925, hoy día sólo subsiste el Decreto sobre lanzamientos.

... hemos afirmado que sin una transformación total de nuestra economía, no podremos transformar la estructura del régimen.

- ¿A qué ideología determinada corresponde esta Revolución? A ninguna. No se sorprenda: nosotros tratamos de hacerle a esta Revolución su peculiar contenido ideológico. Mañana, los que nos sucedan, podrán llamar a nuestras realizaciones con el rótulo que les corresponda" 14 .

La República Socialista promulgó pocos decretos leyes en comparación con los gobiernos de facto posteriores del mismo año 1932, y reguló materias de distinta índole: configuración de agravantes para delitos de robo en lugares públicos ${ }^{15}$; propiedad minera y concesiones ${ }^{16}$; disolución, creación, reorganización de servicios y cambios de dependencia ${ }^{17}$; normas sobre empeño; cabe destacar el Decreto Ley 15, que ordenó a la Caja de Crédito Popular devolver gratuita e inmediatamente “a los empeñantes los respectivos artículos de uso doméstico, prendas de vestir y abrigo, como también máquinas de coser y elementos de trabajo que existen empeñados en esa institución hasta la concurrencia de trescientos mil pesos" por ser "urgente atender de manera inmediata las necesidades del pueblo, en lo que se refiere a proporcionar ropas y elementos de trabajo".

14 Extracto del texto "Lo que dijo Eugenio Matte Hurtado para La Nación de Buenos Aires", recogido en Devés y Díaz (1987), p. 221.

15 Por Decreto Ley No 25 se dictaron normas en relación con los delitos de robo y de hurto, así como respecto de las faltas, modificándose los artículos 494 número 19 y 495 números 21 y 22, 436, 443, 446 y 467 del Código Penal. Así como la Ley No 3988 de 16 de octubre de 1923, también modificatoria del Código Penal.

16 Por el Decreto Ley No 3 suspendió la aplicación de las normas del Código de Minería en lo relativo a nuevas propiedades mineras. Su artículo $2^{\circ}$ dispuso que las concesiones sobre yacimientos minerales de cualquiera naturaleza fueran otorgadas por el Presidente de la República y que las transferencias e hipotecas mineras requirieran autorización del Estado.

17 Así, por ejemplo, por Decreto Ley No 5 reorganizó en lo relativo a su administración la Caja de Retiros y de Previsión Social de los Ferrocarriles del Estado y la Caja de Ahorro reguladas por las leyes Nos. 2.498 de 1.911 y 30.74 de 1916; por Decreto Ley No 20 disolvió el Consejo de Previsión Social, de Empleados y Obreros, regulado por el Decreto Ley No 2.096 de 31 de diciembre de 1927 y radicó sus funciones en la Caja de Empleados Particulares y en el Seguro Obrero; por Decreto Ley No 30 disolvió derechamente la Caja de Crédito Agrario, por cuanto "ha favorecido de preferencia los intereses de los grandes agricultores, desatendiendo los de los pequeños". 
Se estableció en el artículo $5^{\circ}$ que el Ministerio del Trabajo, con el concurso de la Dirección General del Crédito Popular y Casa de Martillo, arbitraría los medios para "entregar a los empleados y obreros cesantes las prendas empeñadas en las agencias particulares, sin excederse en la suma fijada con anterioridad".

También dictó un conjunto de medidas en favor de los comerciantes minoristas $^{18}$.

Se enfrentó la cesantía estableciendo recursos para mantener obras públicas que implicaban dar trabajo a 20 mil personas. Recurriendo, incluso, al expediente de disponer de tierra fiscal y particular para favorecer a los sectores populares: el Decreto Ley No 41, dictado el 16 de junio de 1932 y publicado en el Diario Oficial con fecha 29 de julio de 1932, autorizó al Director de la Caja de Colonización Agrícola para invertir la suma de tres millones de pesos en "la colonización de fundos fiscales, con empleados y obreros cesantes y campesinos; y en la adquisición de terrenos de propiedad particular, aptos para ser colonizados por personas que reúnan las calidades antes indicadas, colonización que deberá llevarse a cabo de acuerdo con el plano elaborado por la Caja ya mencionada”.

Por Decreto Ley No 11 se declaró indispensable "para la República Socialista de Chile" la transformación del Banco Central en Banco del Estado'19.

La última resolución legislativa firmada por Puga y Eugenio Matte es de fecha 16 de junio, aunque fue publicada en el Diario Oficial el 22 de junio.

Todas estas medidas implicaban un cambio, hecho sin sujeción al sistema formal de creación de ley, del orden liberal burgués. El Derecho se mostró dúctil para esta transformación, aunque ello implicaba desahuciar un mecanismo asociado con la democracia: el funcionamiento del Parlamento.

La República Socialista, gobierno de facto, recurrió a legislación irregular. Cabe hacer notar que la Corte Suprema venía validando los decretos leyes desde 1925 (mantuvo la misma doctrina a lo largo del siglo $\mathrm{XX}^{20}$ ).

18 Decretos Leyes Nos. 27 y 28 de 15 de junio de 1932.

19 A través del Decreto Ley No 12 derogó el Decreto Ley No 486 de 22 de agosto de 1925 que creó el Banco Central de Chile, en lo que fuere incompatible con él. Este mismo decreto ley estableció que pasaban a ser propiedad del Estado los créditos y depósitos en moneda extranjera que adeudan al público los bancos nacionales y extranjeros: "con el objeto de evitar injustas ganancias a aquellas personas que, con perjuicio de la economía nacional convirtieron sus depósitos a moneda extranjera, debilitando la posición del Banco Central y provocando la desvalorización de la moneda”.

Por Decreto Ley No 39 de 16 de junio se complementó la normativa en distintos aspectos relativo a la conversión y vencimiento de los depósitos.

20 Por todos véase, SAENGER (2003), pp. 401-462. 
De dicha producción legislativa puede desprenderse un aspecto central en la concepción no dogmática del Partido Socialista de Chile: su componente pluriclasista. Se controló al gran comerciante y al gran productor agrícola para evitar sus excesos. Se amparó al pequeño comerciante, al empleado, al obrero y al campesino.

La Junta, según ya dijimos, señaló al describir sus desafíos que se ocuparía de los males que sufrían las masas de trabajadores cesantes. Daba prioridad la República Socialista a tres tareas urgentes para el Gobierno: "alimentar al pueblo, vestir al pueblo y domiciliar al pueblo, recurriendo para ello a las grandes fortunas" 21 .

\section{LA LEGISLACIÓN IRREGULAR DICTADA POR DÁVILA}

(17 DE JUNIO AL 13 DE SEPTIEMBRE DE 1932), inVOCACIÓN DEL EsTADO SOCIALISTA y COINCIDENCIA CON la República Socialista

A partir del Decreto Ley No 43, dictado el día 17 de junio de 1932, la numeración de los decretos leyes se mantuvo correlativa, pero las nuevas normas se firmaron por Carlos Dávila, Alberto Cabero, Pedro Nolasco Cárdenas y Juan Antonio Ríos.

La acción de Carlos Dávila, ya sea en la Junta que siguió a la República o como Presidente de la República, fue calificada el año 1933 por quienes dieron origen al Partido Socialista de Chile, como una traición a los organizadores de la República Socialista. Sin embargo, la normativa despachada por el Gobierno que encabezó calificaba las medidas que se adoptaron como propias de un "Estado Socialista".

Dávila, uno de los integrantes de la Junta que dio origen a la llamada República Socialista, no obstante su violenta separación con los otros miembros (que fueron responsables en 1933 de la formación del Partido Socialista de Chile), continuó recurriendo al imaginario según el cual se requería una organización socialista para Chile. Si bien es cierto, los historiadores del Partido Socialista (Julio César Jobet, Manuel Dinamarca) consideran que la República Socialista de Chile sólo corresponde al período en que la Junta está integrada por Puga y Matte, en la legislación irregular posterior se menciona en numerosas ocasiones la expresión "tendencias socialistas", "programa socialista del Gobierno", "régimen de Gobierno socialista", "Estado Socialista", "régimen socialista" y "República Socialista"22.

21 “El Manifiesto de los Revolucionarios”, en Devés y Díaz (1987), p. 189.

22 El Decreto Ley No 314 de 26 de agosto de 1932 señaló en el considerando número dos: "Que el esfuerzo innovador de las tendencias socialistas en que se encuentra decididamente empeñado el actual Gobierno, 
Jobet considera que el derrocamiento de la Junta, encabezada por Matte y Grove, fue resultado de "la acción mancomunada de la oligarquía y el imperialismo"23 y de la falta de adopción de "medidas radicales para desmontar la máquina administrativa reaccionaria" 24 ; sin embargo, y a pesar de que la nueva Junta derogó varios de los decretos leyes dictados en el período anterior $(v \cdot g$. el decreto ley que transformaba el Banco Central de Chile en Banco del Estado25), en los hechos corresponde a Carlos Dávila la responsabilidad en la promulgación de una normativa que invoca expresamente fines socialistas como fundamento de su actividad legislativa ${ }^{26}$.

La transformación o reforma del Estado Liberal impulsada por Dávila, ahora separado de Matte y Grove, usa la calificación de socialista para las medidas re-

en beneficio de la clase desvalida, se ve perturbado en la práctica por la acción destructora de elementos anárquicos; lo que redunda en perjuicio del bienestar general y del progreso del país".

El Decreto Ley No 402 de 13 de agosto de 1932 que creó el Departamento de la Habitación para coordinar la solución del problema de las habitaciones populares, dispuso, se crea una unidad "que permita desarrollar de manera armónica el programa socialista del Gobierno".

El Decreto Ley No 365 de 12 de agosto de 1932 resolvió pagar las dietas parlamentarias porque el decreto número 1757 de 6 de junio de 1932 que declaró disuelto el Congreso Nacional "no derogó las disposiciones del artículo $7^{\circ}$ transitorio de la Constitución Política, que estableció el monto de la dieta parlamentaria, ni la Ley No 5.105 de 18 de abril, por la cual se la redujo para financiar la Ley de Cesantía”. Agregando el considerando tercero. "Que el espíritu general de la legislación señala la obligación de indemnizar los perjuicios que se ocasionaren, y esta obligación es más evidente en un régimen de Gobierno Socialista, que persigue la realización de la justicia social...”.

El Decreto Ley No 521 de 31 de agosto de 1932 que creó el Consejo de Economía Nacional señala a este respecto que “... es obligación primordial del Estado Socialista velar porque todos los habitantes del país tengan trabajo permanente y remunerativo...".

El Decreto Ley No 473 de 23 de agosto de 1932 empleaba estas dos últimas expresiones a propósito de la creación del Departamento de Extensión Sociológica y Cultural que reemplazó al Departamento de Bibliotecas en el Ministerio del Trabajo. Señala en sus considerandos: "Que conforme a la nueva orientación política del Estado, el personal administrativo debe secundar, con la mayor eficiencia posible, la ideología y la realización de la República Socialista”.

Se dispuso que la "Sección Propaganda atenderá la difusión general de las leyes sociales y de la doctrina socialista...".

23 Jobet (2015), pp. 35-37.

24 Idem.

25 La importancia económica de esta medida puede verse en DraKe (2004).

26 Según STEMPlowski (1988), “... subrayaba la moderación de Dávila, aunque se reconocían los decretosleyes sobre la creación del Instituto de Comercio Exterior y sobre el Comisariato de Subsistencia y Precios que promulgó, como medidas afines al bolchevismo".

A la vez, el diplomático llamaba la atención que en Chile se utilizaban las nociones de comunismo y socialismo de manera diferente que en Europa y que, según su opinión, "no significaban mucho", aunque califica las medidas como propias de un Estado socialista. 
formistas. Lo cual implicó que se usó el Derecho para adjetivar, de cara al país, al nuevo orden de cosas que se quería construir.

Los decretos leyes expresaban en este sentido una visión de Estado Socialista. $\mathrm{Su}$ análisis permite determinar qué significaban las expresiones Gobierno Socialista, Régimen de Gobierno Socialista, Estado Socialista, según la comprensión que proponía Carlos Dávila.

Las normas que se promulgaron, aunque no configuran un Estado Socialista propiamente tal, constituyen el punto de partida de una estructura estatal que atenderá activamente cuestiones de naturaleza económica y social. Fórmula que será identificada desde entonces por quienes defienden las ideas liberales, como Estado socialista. La toma de posición frente a dichas medidas por los sectores que promueven el ideario económico liberal, implicó calificar como socialista a cualquiera propuesta que implicara una mayor participación del Estado en la actividad económica y/o una intervención limitando el despliegue de la ley de oferta y demanda.

Para los detractores del socialismo poca importancia tiene si el uso que hace Dávila de las voces Estado socialista, gobierno socialista y otras semejantes, se refieren a un auténtico socialismo o sólo a un socialismo de Estado ${ }^{27}$. A los ojos de los detractores del Estado socialista, todo Estado interventor del libre juego de la oferta y la demanda, así como actor de la vida económica, era tal Estado. Y los decretos leyes avalaban esta calificación porque Dávila llamó socialista a un mero Estado interventor: la expresión no se refería a un Estado de economía centralmente planificada y propiedad estatal de los medios de producción. En efecto, lo generado en los meses de junio y septiembre de 1932 se inserta en el modelo denominado socialismo de Estado.

Dávila expresa con esta normativa una propuesta distinta de la ibañista y de la corporativista ${ }^{28}$. Cabe hacer notar que recientemente Luis Corvalán M. (2015), no realiza ninguna vinculación del Movimiento Nacional Socialista con Carlos Dávila.

27 Una expresión de esta perspectiva se encuentra en el ataque de los Chicago Boys al Estado interventor gestado desde esta década de 1930 (véase por todos el trabajo de Buchi -1993- que da cuenta del desmantelamiento del Estado Interventor chileno, que los Chicago denominan Socialista).

28 Castillo-Figueroa et al. (2005) sostienen que Dávila tenía un ideario cercano, pero autónomo de Carlos Ibáñez del Campo. Exploran la propuesta de Mario Góngora y de Susana Simonetti de acercar a Dávila al corporativismo italiano y alemán, afirmando que carece de suficiente fundamento de fondo y que esos elementos identificados como comunes, incluso, se podrían señalar respecto de todo el socialismo chileno, incluido Grove. 
Se ha escrito al respecto que las acciones de este Estado interventor pueden entenderse tanto como decisiones de uno capitalista, en la medida que las intervenciones se realizan para salvar al capitalismo, como de preparación del advenimiento de uno socialista:

"A decir verdad, el cambio tuvo en Chile dos vertientes: una reformista y otra socialista. En efecto, por una parte, los defensores del sistema capitalista en Chile, influidos por la escuela Keynesiana, postularon decisivamente la existencia de un Estado intervencionista. Pero, a la acción deliberada, consciente, aunque no confesada, del cambio para la conservación, se sumó más de una vez -y en algunas oportunidades prevaleció-, una acción de distinto signo, propia de los partidos que propugnaban realmente un cambio. Estos partidos también propiciaban un cambio de la concepción del rol del Estado en la economía, es decir, también propiciaban el establecimiento del Estado intervencionista; pero, como una etapa previa, necesaria, que pondría fin a ciertas injusticias sociales y que permitiría, más adelante, una gradual socialización de la economía" 29.

A la luz de los valores, ideales, justificaciones y anhelos que se transmitían en los textos legales que se fueron generando con ánimo de alterar el orden de cosas, nos parece más plausible la segunda interpretación.

Así tenemos que por Decreto Ley No 473 de 23 de agosto de 1932, se creó el Departamento de Extensión Sociológica y Cultural que reemplazó al Departamento de Bibliotecas en el Ministerio del Trabajo. Señalaba en sus considerandos:

"Que entre el personal de la Administración Pública, los funcionarios del Ministerio del Trabajo, sobre todo en el momento actual de transformación estructural de la República, constituyen un factor de trascendencia máxima para el afianzamiento definitivo del régimen socialista... Que es de necesidad imprescindible y urgente formar en todos los ciudadanos una conciencia precisa y categórica de sus derechos y deberes, en armonía con los principios fundamentales de justicia social... Que conforme a la nueva orientación política del Estado, el personal administrativo debe secundar, con la mayor eficiencia posible, la ideología y la realización de la República Socialista”.

Se dispuso: la "Sección Propaganda atenderá la difusión general de las leyes sociales y de la doctrina socialista...”; ... a la Sección Espectáculos se le encargó propender a la "creación del Teatro del Pueblo, que ejercerá marcada influencia en la orientación del pensamiento de las masas populares".

29 SulE (1980). "El avance hacia el socialismo. La experiencia del Gobierno de la UP en Chile", en Nueva Sociedad (número 46), pp. 101-109, 106. 
Bajo el Gobierno de Dávila hubo una importante modificación del sistema tributario que implicó un aumento del Impuesto Global Complementario; del Impuesto a la Renta, estableciéndose además la progresividad de las tasas; de las contribuciones; de timbres, estampillas y papel sellado, y se estableció por una sola vez un impuesto a la compraventa de bienes raíces. Por Decreto Ley No 364 se reguló el impuesto a la herencia y donaciones. Se estimó necesario facilitar el pago, pero también "aumentar las tasas, no tan sólo porque así lo exijan las circunstancias difíciles del Erario, sino también porque así lo ordena una política de verdadera justicia social". La coincidencia en este punto con la Junta que instauró la República Socialista es significativa. El 5 de junio en su proclama al país ella señaló: "Para evitar la injusticia que significa la desigual repartición de la riqueza, se modificará el sistema tributario gravando las grandes rentas. Mientras esta modificación se realiza, se impondrá desde luego un impuesto extraordinario y progresivo a las fortunas superiores a un millón de pesos"30.

Además, y en relación con las tres tareas urgentes del Gobierno ya referidas, por Decreto Ley No 281 de 10 de agosto de 1932 se autorizó al Presidente de la República para que declarara, por sí o a solicitud de los productores, determinado artículo de producción fabril en sobreproducción. La relevancia de esta declaración la expresa el artículo $2^{\circ}$ :

"Declarado el estado de sobreproducción sólo podrán instalarse nuevas fábricas del artículo respectivo, previa autorización del Presidente de la República otorgada por decreto supremo;... Artículo 3. En los casos en que se haya declarado el estado de sobreproducción, el Presidente de la República establecerá las calidades, envases y precios de venta del artículo, armonizado con sus costos de producción y distribución y, además, impedirá los acaparamientos y especulaciones comerciales con el artículo, que se hagan con fines de competencia desleal o lucro excesivo en perjuicio del consumidor. Asimismo, el Presidente de la República podrá adoptar medidas encaminadas a obtener el acuerdo de los fabricantes del artículo declarado en sobreproducción para modificar la organización, procedimientos de elaboración y ubicación de la industria, siempre que con ello se obtenga más eficiencia o mayor beneficio para la economía nacional".

Por Decreto Ley No 353 de 11 de agosto de 1932 se estableció el precio máximo del trigo, la harina y el pan, fijándose precios diferenciados según ciudades, así, por ejemplo, el del pan no podrá ser superior a \$1.20 el kilo en las ciudades de

30 “La Junta de Gobierno al País", 5 de junio de 1932, en Devés y Díaz (1987), p. 191. 
Ovalle y Santiago y no superior a \$ 1.15 en las de Talcahuano, Valdivia y Puerto Montt "vendido en mesones de panaderías, almacenes o depósitos, por cualquiera cantidad y medida" 31 .

La gravedad de la crisis que está en la base de toda esta normativa, y cuyo antecedente directo es la debacle del modelo político y económico capitalista (Primera Guerra Mundial y Gran Depresión) implicó la regulación por el Decreto Ley No 520 en su Título V, de las “cocinas populares". Se facultó al Comisariato General de Subsistencias y Precios para que propusiera al Presidente "cocinas populares, por cuenta del Estado, para proporcionar comida a bajo precio. Estará facultado, asimismo, para fomentar la explotación por particulares de cocinas populares"32.

Por Decreto Ley No 465 se renovaron los fondos para la alimentación de los cesantes.

Por Decreto Ley No 436 se condonó los intereses penales cobrados a los indigentes por el no pago de los servicios de agua potable.

El Decreto Ley No 533 dispuso la suspensión por el plazo de 60 días, de los juicios iniciados por propietarios o vendedores en contra de la población compradora o arrendadora de sitios en poblaciones obreras urbanizadas o no, "sea que con la demanda persiga el pago del precio o renta, la nulidad, resolución o terminación del contrato, o las restitución del predio".

En atención a los altos niveles de cesantía, por Decreto Ley No 113 de fecha 19 de julio de 1932 fijó "por el plazo de un año, la jornada máxima diaria de trabajo en los establecimientos industriales y comerciales del país" en ocho horas, "quedando suprimido todo trabajo extraordinario, salvo las excepciones que estableciere la Inspección del Trabajo", para lo cual los establecimientos afectados deberán solicitarlo por escrito. El artículo segundo facultó a la Inspección del Trabajo "para establecer, previo estudio con los obreros y patrones interesados, una jornada menor que la anterior hasta el límite de 4 horas diarias".

31 Por Decreto Ley No 590 de 13 de septiembre de 1932 se dispuso que ante la limitada disponibilidad de trigo y harina, y siendo "obligación del Gobierno velar por las subsistencias de primera necesidad a fin de que el pueblo disponga de éstas en las más ventajosas condiciones", lo que exige "que "pueda abaratarse el precio de la harina y el pan y reducirse a una cantidad mínima la internación de ese cereal", sólo podrá producirse "harina integral, es decir, aquella que contenga las harinas flor, de segunda y tercera, la harinilla y el afrechillo... pero en ningún caso el rendimiento total de 100 kilogramos de trigo podrá ser menor al 83 por ciento". 32 El 5 de junio se había declarado a este respecto: "El Gobierno reconoce como uno de sus deberes fundamentales asegurar la subsistencia de cada uno de los individuos de la colectividad, usando de todos los medios de que dispone el país". Y a mayor abundamiento: "Se intensificará bajo el control de las organizaciones obreras, el reparto de víveres, utilizando también el personal y los elementos de movilización y preparación de que dispone el Ejército". (“La Junta de Gobierno al País”, en Devés y Díaz (1987), pp. 190 y 191). 
Se creó la Dirección General de Cesantía con la misión de atender a los cesantes y de ocuparse de arbitrar los medios para que accedan a trabajo. Se le encargó por el artículo $6^{\circ}$ del Decreto Ley No 228 formar un "censo de desocupados por profesión y oficio, a objeto de que seleccionando esos elementos, pueda impulsar la formación o desarrollo de pequeñas industrias, bajo tuición del Estado y proporcionar los más preparados que requieran los servicios de otros Ministerios y de la industria privada".

El Decreto Ley No 521 de 31 de agosto de 1932 creó el Consejo de Economía Nacional y dejó establecido en sus considerandos: "1. Que es obligación primordial del Estado Socialista velar porque todos los habitantes del país tengan trabajo permanente y remunerativo, especialmente en las circunstancias actuales, en que la cesantía constituye un grave problema social de solución impostergable". La normativa reconoce un nivel de cesantía de 100 mil obreros y una bajísima capacidad productiva en las industrias minera, agrícola y manufacturera, por lo que se propone en el tercer considerando la formulación de un "plan racional y armónico de producción”. Agregando en los considerandos quinto y sexto que corresponde: “... efectuar inversiones por el Estado y dotar a los productores de los capitales indispensables y a bajo interés que les aseguren una regular y permanente explotación de sus industrias... y la creación de ciertos organismos fiscales autónomos que tomen a su cargo explotaciones mineras e industriales de interés nacional, con fines comerciales”. Se dispuso entonces en el artículo segundo formular un "Plan de Emergencia destinado a la reconstrucción económica del país y absorción de la cesantía, mediante el desarrollo de las industrias minera, agrícola, fabriles y pesqueras, comercio y obras públicas".

Por Decreto Ley No 164 de 9 de julio de 1932 el Gobierno de Dávila dictó una muy avanzada normativa en términos de reinserción social de quienes delinquen: "Considerando que es deber del Estado preocuparse de la situación de las familias de los reos, tanto para atender sus necesidades inmediatas como para propender a su perfeccionamiento moral y material" dispuso la fundación en diversas ciudades de talleres y hogares para "los deudos de los reos".

Señala a este respecto el texto legal:

"Artículo 1: Créase en las ciudades de Santiago, Antofagasta, Valparaíso, Rancagua, Curicó, Talca, Concepción, Temuco y Valdivia, talleres de costura, lavandería, etc., para dar trabajo en ellos a las esposas, hijas y hermanas de los reos.

Anexos a estos talleres funcionarán hogares para los hijos menores de los mismos reos. 
Art. 2. Las personas que se ocupen en estos talleres trabajarán cinco horas al día y estarán, además, obligadas a asistir durante tres horas diarias, a escuelas vocacionales y primarias.

Art. 3. La organización y funcionamiento de estos talleres y hogares estarán a cargo de la Dirección General de Prisiones".

Los artículos 4, 5 y 6 regularon las fuentes de financiamiento de las medidas.

El Decreto Ley No 409 de 18 de agosto de 1932 abordó el problema que implicaba para el presidiario que había cumplido su pena quedar "marcado para toda su vida con el estigma de haber sido presidiario". Se estimó que "El Estado debe velar porque los egresados de las prisiones que estén sin trabajo no carezcan de techo ni de alimentación, y se les ayude en toda forma, como una medida de protección al individuo y de defensa de la sociedad"33.

Por Decreto Ley No 331 de 10 de agosto de 1932 estableció en relación con la Caja de Seguro Obrero Obligatorio que: "Estas imposiciones permanecerán, por iguales partes con derecho a acrecer, al cónyuge sobreviviente, a los legitimarios y a los hijos ilegítimos del asegurado”.

El Estado asumía de esta manera un rol de protección de sectores tradicionalmente estigmatizados como el de los delincuentes pobres y los hijos ilegítimos. Poniendo de relieve la importancia que los problemas e intereses de los sectores populares pasaban a jugar en el Estado activo que se estaba diseñando.

Por Decreto Ley No 472 esta nueva fórmula estatal invoca la "legislación social internacional" y los derechos en ella consagrados, y en particular el Convenio Internacional sobre limitación del número de horas de trabajo, aprobado en la primera Conferencia Internacional del Trabajo de 28 de noviembre de 1919, y ratificado por Chile mediante el Decreto Ley No 464 de 10 de agosto de 1925, para adoptar medidas relativas a la regulación de la jornada de trabajo.

Por Decretos Leyes Nos. 127 y 435 se reguló las operaciones mercantiles del Banco Central con distintas Cajas. Se autorizó a las mismas para otorgar créditos para el desarrollo de actividades agrícolas, mineras e industriales.

33 Dispuso el artículo primero: "Toda persona que haya sufrido cualquiera clase de condena y reúna las condiciones que señala esta ley, tendrá derecho, después de dos años de haber cumplido su pena, si es primera condena, y de cinco años, si ha sido condenado dos o más veces, a que por decreto supremo de carácter confidencial, se le considere como si nunca hubiere delinquido para todos los efectos legales y administrativos y se le indulten todas las penas accesorias a que estuviere condenado.

El decreto que concede este beneficio se considerará como una recomendación del Supremo Gobierno al Senado para los efectos de la rehabilitación a que se refiere el número 2 del artículo 9 de la Constitución Política”. 
El Decreto Ley No 48 de 20 de junio de 1932 contiene una larga exposición de motivos donde se señala expresamente el daño que han provocado a productores y comerciantes las acciones especulativas de: "algunos audaces hombres de negocios, con perjuicios de la producción que desorganiza y los más elementales principios de la ética que vedan la especulación en tierras en la forma que se está haciendo, como debieran vedar la especulación en moneda extranjera que se hizo antes, con grave perjuicio de la colectividad entera" 34 .

La normativa reguló las tasas de interés y las modalidades de pago y de cobro de obligaciones pecuniarias contraídas entre comerciantes, así como entre particulares no comerciantes. Suspendió las ejecuciones, concursos y quiebras pendientes ${ }^{35}$.

Bajo el paraguas de las voces Estado socialista, gobierno socialista, régimen de gobierno socialista e ideas socialistas, Carlos Dávila desplegó un conjunto de medidas que limitaban el accionar del empresariado chileno, llegando incluso a regular acciones del capitalismo financiero.

Se ordenó que todo seguro de accidentes del trabajo que debían tomar el Fisco, las municipalidades y toda institución dependiente directa o indirectamente del Estado debía contratarse con la Sección del Trabajo de la Caja Nacional de Ahorros, sin intervención de agentes o intermediarios, para impedir que se lucrara con un beneficio social.

Ello implicaba retirar el lucro de la seguridad social, avalando la mirada internacional y nacional según la cual la seguridad social era un derecho y no un mero contrato de seguros entre particulares.

El interés por desplazar al mercado y al lucro de ciertas áreas de la economía se manifestó también en la normativa sobre accidentes del trabajo: se privó a las compañías de seguro de este negocio y se hizo responsable al Estado ${ }^{36}$. Se dispuso que el Seguro de Accidentes del Trabajo pasaba a ser "una función social y podrá ser contratado solamente en la Sección de Accidentes del Trabajo de la Caja Nacional de Ahorros... La Sección hará el seguro de accidentes del trabajo sin propósito de ganancia”.

En otra materia de enorme relevancia, el "Estudio de la organización de una Asamblea Constituyente a base funcional, que dictará la nueva Carta

34 La Junta señaló el 5 de junio: "El crédito debe ser controlado por el Estado en beneficio de la colectividad, para evitar la explotación de los que trabajan por el capitalismo", "La Junta de Gobierno al País", en Devés y Díaz (1987), p. 190.

35 Derogó el Decreto Ley No 27 de 15 de junio de 1932.

36 El Decreto Ley No 367 de 3 de agosto de 1932, tramitado pero no publicado. 
Fundamental" 37 , contemplada como número 27 de los treinta puntos básicos de acción inmediata, aconteció que por Decreto Ley No 476 de 25 de agosto de 1932 se convocó a "elecciones generales de un Congreso Constituyente para el 30 de octubre de 1932" 38 . La fundamentación de la convocatoria es expresiva de la concepción política que está en la base del Estado que se promueve, y al que se insiste en calificar como Estado Socialista:

"El proceso revolucionario destinado a cambiar la estructura económica, social y política del país, debe ser sancionado por la opinión popular.

El Gobierno, consecuente con sus principios y declaraciones, desea que esa opinión se manifieste en forma amplia, en los comicios de octubre.

Abatidos por la revolución los baluartes donde se asilaba un régimen institucional que oprimía una realidad social, el Gobierno espera que estas elecciones, amparadas por la más absoluta libertad, sean una sincera expresión del pensamiento público y produzcan la normalización política de la Nación.

El Gobierno que, por una parte está venciendo los fermentos de anarquía que amenazan la estructura nacional y, por otra, se mantiene y mantendrá libre de las influencias tradicionales que malograron la representación pública, ofrece lealmente al pueblo la oportunidad de darse las normas y poderes que, está cierto, habrán de consolidar las etapas realizadas de la revolución socialista...

Las elecciones de senadores y diputados deben afinar conceptos nuevos en la vida republicana, que hagan compatible la legalidad con la acción niveladora del Estado. La normalidad debe ampararse en la nueva Constitución y ésta debe fundarse en los intereses y sentimientos del pueblo. Mantener la soberanía popular dentro del aislamiento de una violencia jurídica, sería provocar una crisis, pero avocada ahora, a un caos sin remedio.

Por eso será necesario que intervengan en esta consulta nacional, elementos antes apartados de las urnas, que trabajan y contribuyen activamente al desenvolvimiento del país y que el elector exprese, más que sus intereses políticos, su pensamiento ciudadano frente a los problemas económicos y sociales de Chile”.

37 En Devés y Díaz (1987), p. 200.

38 Lo firmaban Carlos Dávila, Joaquín Fernández F., Ernesto Barros J., Luis Barriga Errázuriz, Luis D. Cruz Ocampo, Víctor M. Navarrete, G. M. Bañados, Pedro Lagos, M. Montalva, Juan B. Rossetti, Dr. A. Quijano y Arturo Riveros. 
Dispuso el artículo 10 "Convócase a elecciones generales de un Congreso Constituyente de senadores y diputados, para el domingo 30 de octubre, a fin de que, constituidos en Congreso Pleno, se pronuncien sobre el proyecto de Carta Fundamental que el Gobierno someterá a su deliberación”. Finalizada su tarea, los diputados y senadores electos pasarían a integrar la Cámaras Legislativas.

En relación con otras materias, la "reorganización de la administración de Justicia" (punto 29 de Los treinta puntos básicos de acción inmediata de la Junta del 4 de junio ) $)^{39}$, Dávila reguló por medio del Decreto Ley No 207 de 24 de agosto de 1932, el asiento, jurisdicción, planta y sueldo de los integrantes de los Tribunales del Trabajo. Determinó Tribunales de Alzada en Iquique, Valparaíso, Santiago y Concepción y fijó su jurisdicción. Cifró en cinco los Juzgado del Trabajo de Santiago y en tres los de Valparaíso, a los que llamó de primera clase. Prohibió a los presidentes de Tribunales de Alzada y los jueces del trabajo de primera clase ejercer la profesión de abogado.

Por Decreto Ley No 488 de 27 de agosto de 1932 se aprobó un nuevo Código de Minería de un total de 248 artículos y un artículo final que declaró "quedarán derogadas, aún en la parte en que no fueren contrarias a él, las leyes, ordenanzas y demás disposiciones especiales preexistentes sobre la materia”.

El artículo primero estableció:

"El Estado es dueño de todas las minas de oro, plata, cobre, azogue, estaño, piedras preciosas y demás substancias fósiles, no obstante el dominio de las corporaciones o de los particulares sobre la superficie de la tierra en cuyas entrañas estuvieren situadas.

Pero se concede a los particulares la facultad de catar y cavar en tierras de cualquier dominio para buscar las minas a que se refiere el precedente inciso, la de labrar y beneficiar dichas minas, y la de suponer de ellas como dueños, con los requisitos y bajo las reglas que prescribe el presente Código".

El Decreto Ley No 519 sometió "al control del Estado la importación de petróleo y sus derivados, la distribución en el país y su venta a los comerciantes y consumidores". Creó la Dirección de Abastecimiento de Petróleo y fijó su planta y sueldos ${ }^{40}$.

39 En Devés y Díaz (1987), p. 200.

40 La relevancia de esta medida en relación al conflicto con las empresas norteamericanas West India Oil Co. y la Shell-Mex (Chile), puede verse en el trabajo DE STEMPLOWSKI (1978). 
Las medidas descritas hasta ahora implicaban que sectores claves, como la explotación minera y petrolera, pasaban a quedar bajo la tuición estatal. Por ende, se limitaba el control del mundo privado empresarial sobre sectores productivos de enorme relevancia económica ${ }^{41}$.

Dinamarca, según ya vimos, atribuye a la experiencia de la República Socialista la autoría del Decreto Ley No 52042; sin embargo, el mismo fue publicado en el Diario Oficial el 31 de agosto y el 5 de septiembre de 1932, con las firmas de Carlos Dávila, Joaquín Fernández y Luis Cruz Ocampo.

El Decreto Ley No 520 creó el Comisariato General de Subsistencias y Precios, ente con personalidad jurídica dependiente del Ministerio del Trabajo. Se integraba por tres consejos (de alimentación, vestuario y artículos de primera necesidad y de transporte, calefacción y alumbrado). Contempló la posibilidad de instalar los comisariatos en cualquier lugar del país.

Se le asignó al Comisariato General de Subsistencias y Precios como objetivo "asegurar a los habitantes de la República las más convenientes condiciones económicas de vida".

De acuerdo con el artículo tercero dicha finalidad se alcanzaría:

“... de preferencia, mediante la adquisición y el control de la calidad y precio de los artículos de primera necesidad y de uso o consumo habitual, en todo lo que respecte a alimentos, vestuario, calefacción, alumbrado, transportes, productos medicinales y materias primas de dichas especies y servicios, atendidos para la fijación de precios, los costos de producción, gastos inevitables y utilidades legítimas".

Como es evidente y se desprende del tenor literal, la normativa no pretendía expropiar la producción y menos todavía ignorar el costo de elaboración del bien. La cuestión más relevante era la de las utilidades. El Gobierno cuestionó la cuantía de las utilidades obtenidas y se propuso limitarlas a niveles considerados socialmente, no individualmente, como legítimos.

Por el contrario, el decreto ley sí contempló la posibilidad de la expropiación de predios agrícolas, empresas industriales y de comercio y de establecimientos dedicados a la producción y distribución de artículos de primera necesidad. De

41 Al respecto la Junta había señalado el 5 de junio: "Si es necesario, el Gobierno procederá de inmediato a tomar por su cuenta las importaciones de azúcar, petróleo, bencina y demás artículos de primera necesidad”. Devés y Díaz (1987), p. 190.

42 Dinamarca (1987), que a su vez cita a Mireya Villa López.

El decreto ley derogó la Ley No 5.125 de 17 de mayo de 1932. 
acuerdo con el artículo cuarto "Para el sólo efecto de atender a las necesidades imperiosas de la subsistencia del pueblo..." se les declaró de utilidad pública.

Se autorizó la expropiación en casos determinados:

"Art. 5. Todo establecimiento industrial o comercial, y toda explotación agrícola que se mantenga en receso, podrá ser expropiada por el Presidente de la República, a solicitud del Comisariato General de Subsistencias y Precios, previo informe favorable del Consejo de Defensa Fiscal y del Consejo Técnico respectivo.

Art. 6. El Presidente de la República a propuesta del Comisariato General, podrá imponer a los productores la obligación de producir o elaborar artículos declarados de primera necesidad, en las cantidades, calidades y condiciones que determine.

El incumplimiento de dicha obligación lo autorizará para expropiar, con los requisitos señalados en el artículo anterior, el establecimiento, empresa o explotación del productor rebelde, todo sin perjuicio de las demás sanciones que establece esta ley.

Art. 7. Decretada la expropiación, el Comisariato tomará, desde luego, posesión de los bienes expropiados. En lo demás la expropiación se regirá por las disposiciones contenidas en el Libro IV, Título XVI, del Código de Procedimiento Civil.

Art. 8. El Comisariato podrá explotar directamente las empresas que se expropien”43.

A fin de garantizar un grado de racionalidad en la fijación de los precios y evitar de ese modo el desincentivo absoluto a la producción, se dispuso que podía también "Investigar los precios al por mayor de los artículos de primera necesidad y de uso o consumo habitual, así como su costo de producción" y "estudiar el estado de las industrias" en lo tocante a los artículos mencionados ${ }^{44}$.

El artículo 29 dispuso: "El comisariato pagará las mercaderías que adquiera dentro del país, al precio fijado para su expendio a los productores y distribuidores mayoristas". Respecto del precio de venta se estableció expresamente que el Comisariato "no podrá vender a precios inferiores a los fijados al comercio detallista".

La gestión de todos los comisariatos quedó sometida a la Contraloría General de la República, la que, según el artículo 68, "examinará mensualmente las cuentas".

De acuerdo con el artículo 11: "El Estado garantizará un interés hasta de seis por ciento a los capitales privados que se aporten a las nuevas Empresas en que

43 Contraloría General de la República (1933), pp. 475-476.

44 El Decreto Ley No 530 de 31 de agosto de 1932 creó la Dirección General de Estadísticas. 
tengan participación y que se establezcan de acuerdo con las autorizaciones a que se refiere". El mismo decreto ley en su artículo 12 dispuso que la constitución de empresas "será materia de una ley especial".

No cabe perder de vista el escenario socioeconómico del Chile de la época: el país venía soportando desde el año de 1919 la crisis de la fórmula económica liberal capitalista, agravada con la depresión de 1929.

Los tres últimos decretos leyes dictados por el Presidente Carlos Dávila (632, 633 y 635) se refieren a casos particulares relacionados con pensiones.

Dávila dictó otras medidas comprensivas tanto de cuestiones de tipo institucional, como creación y alteración de servicios y regulación de potestades de autoridades, como relativas a las relaciones entre trabajadores y empleadores. Apuntando todas ellas al fortalecimiento de los servicios públicos, una mejor posición de los trabajadores y la aplicación de la normativa del Código Laboral dictado recientemente ${ }^{45}$.

Toda esta legislación fue objeto de duro cuestionamiento por la Comisión de Estudio de los decretos leyes y decretos con fuerza de ley, designada por Alessandri Palma. Los juristas convocados llegaron, entre otras, a las siguientes conclusiones: que el período junio-septiembre de 1932 fue una etapa de anarquía; que la normativa había sido dictada por un "Gobierno revolucionario"; que la misma era nula por haber violado la Constitución de 1925; que parte

45 Sin ánimo de agotar su tratamiento podemos señalar otras cuestiones reguladas: rentas de arrendamientos de predios urbanos o rurales; pensiones; sueldo del profesorado de educación secundaria, normal, comercial, industrial y física; regulación de la educación rural y dentro de ella de las reducciones de indígenas; dispuso que los sindicatos industriales y profesionales de Magallanes podían designar delegados ante el Directorio respectivo, los que tendrían las prerrogativas de los directores y candidatos a directores de sindicatos; modificó las normas sobre ascensos en el cuerpo de Carabineros; creó el cargo de Secretario General de Gobierno (Decreto Ley No 73 de 25 de junio de 1932); el Ministerio de Guerra y Aviación y el Ministerio de Marina; reguló los derechos de aduana entre Chile y Perú; hizo depender al Consejo de Censura Cinematográfica del Ministerio de Educación Pública; descentralizó la Caja de Crédito Agrario y la convirtió en un ente autónomo respecto de la Caja de Crédito Hipotecario; creó la Dirección General de Tierras y Colonización; implementó la planta del Ministerio del Trabajo y del Archivo General del Registro Civil; fijó la planta y sueldo del personal del Ministerio del Interior; mantuvo actividades que generaban empleo y que dependían de la inversión estatal (construcción del edificio del Ministerio de Hacienda que implicaba contratar un promedio de mil obreros); creó por Decreto Ley No 530 de 13 de septiembre de 1932 con carácter de servicio autónomo dependiente del Presidente de la República, la Dirección General de Estadística; dictó normas sobre uso de los bienes nacionales. Por Decreto Ley No 258 publicado en el Diario Oficial del día 26 de julio de 1932 se estableció la Ley Orgánica de la Contraloría General de la República. El Decreto Ley No 460 dispuso que el Consejo de Defensa Fiscal debía constituirse en un ente autónomo de los Ministerios bajo supervigilancia del Presidente de la República, por lo que modificó el D.F.L. No 246 de 20 de mayo de 1931, Ley Orgánica de dicho Consejo. 
importante de ella atentaba contra "numerosos y fundamentales principios sustantivos" de la Constitución de 1925; que adoleció de una "ideología... contraria a las conveniencias nacionales". El análisis de su razonamiento jurídico permite concluir que temían que la consolidación de las disposiciones amenazara el derecho tradicional, es decir, la normativa liberal burguesa y la misma Carta de 1925 (derechos garantizados en la Constitución y materias reguladas en los códigos) ${ }^{46}$.

Según da cuenta el mismo Informe, la reacción de los poderes del Estado fue distinta: la Corte Suprema, el Ejecutivo y el Legislativo aceptaron la existencia de varios de ellos y no cuestionaron su validez.

La legislación irregular impulsada por Dávila fue empleada por el Gobierno de la Unidad Popular. El uso por el Gobierno de Allende de esta normativa jurídica, que expresa un socialismo de Estado y no un auténtico Estado Socialista, revela que la regulación jurídica del rol activo del Estado (cuestión no necesariamente socialista, aunque se presente a la opinión pública como tal), dejó a disposición del socialismo chileno instrumentos institucionales y regulaciones en sentido estricto, con potencialidad para servir a la construcción de una sociedad socialista según la visión criolla del socialismo.

¿La cuestión es, si sólo el Gobierno de la Unidad Popular puede vincularse con estas medidas de Carlos Dávila? ¿Las decisiones adoptadas y sancionadas por Dávila en los decretos leyes bajo la denominación de medidas socialistas, resultaron absolutamente extrañas y contradictorias con las ideas y la práctica del socialismo chileno luego de la fundación del Partido en abril de 1933? ¿A la luz de toda la normativa presentada, cabe sostener que la dictada por Carlos Dávila una vez que rompe con la Junta de principios de junio de 1932, configura una negación de lo hecho por la denominada República Socialista? ¿En qué medida Dávila traiciona la política de cambios destinada a modificar y sustituir el ideario liberal? ¿El uso de las voces Estado socialista, Gobierno socialista, Régimen socialista, implicó una distorsión o más bien contribuyó a la identificación de las acciones de una política socioeconómica socialista según como la practicó y entendió el socialismo criollo?

Todo parece indicar que la circunstancia que Dávila rompiera sus lealtades con Matte y Grove, no afectó la promesa de cambio en lo social y económico que

46 Informe Jurídico de la Comisión nombrada por el Supremo Gobierno para el Estudio de los Decretos con Fuerza de Ley (1933), pp. 6, 7, 12 y 13. 
la República Socialista encarnó ${ }^{47}$; de hecho, Dávila hizo un uso abusivo de las voces socialista y socialismo. Las medidas adoptadas incluso superaron la promesa de alimentar, domiciliar y abrigar al pueblo, y el Decreto Ley No 520 terminó sirviendo al Gobierno de la Unidad Popular para llevar adelante su proyecto socioeconómico ${ }^{48}$.

No se trata de sostener que Dávila institucionalizó el Estado Socialista en 1932, tampoco que él debe ser considerado un socialista, sino que el reformismo que encarnó en institucionalidad y regulaciones no resultó opuesto ni contradictorio con el accionar de los auténticos socialistas criollos. Todo lo cual permite sostener que hay más puntos de contacto entre los gobiernos del año 1932 que enarbolaron las banderas del socialismo (aunque Dávila exprese un socialismo de Estado), que contradicciones y oposiciones insalvables.

Todo lo cual lleva implícito que el socialismo criollo se ha venido comportando, desde 1933, como un partido reformista más que uno revolucionario.

Si se examinan las medidas adoptadas a la luz de la investigación realizada por Boris Yopo sobre las relaciones del Partido Socialista y Grove con Estados Unidos, la proximidad con Dávila se hace más nítida. Yopo califica a Grove como "partidario de la experiencia roosveltiana” y sostiene que aceptó el rol del Estado capitalista de la sociedad industrial como "organismo de servicio social" generador de una economía de bienestar ${ }^{49}$. Afirma que Grove avanzó en la década de 1940 hacia posiciones cercanas al New Deal.

Yopo recupera el planteamiento de Grove del año 1934 según el cual "los objetivos de la República Socialista de 1932, eran los mismos que ha implementado la administración del gran presidente Roosevelt en Norteamérica" ${ }^{50}$. Cabe recordar que una parte importante de la literatura que analiza las posibilidades del socialismo en Estados Unidos, considera que el año 1933 abrió una coyuntura muy promisoria para la emergencia de un partido socialista ${ }^{51}$.

47 Para una opinión distinta véase de CASANUEVA y FernÁndez (1973), p. 91, que señalan a este respecto "el epíteto socialista fue una máscara utilizada para ocultar las verdaderas características reaccionarias y represivas del grupo que derribó el Gobierno de Matte y Grove... Se trataba en verdad del Gobierno de la oligarquía al desnudo... sin siquiera una Constitución que limitara sus poderes".

48 Véase de Novoa (1970-1971), pp. 26-38.

49 Yopo (1984), pp. 41-44.

50 Yopo (1984), p. 47. Véase también, pp. 85 y ss.

51 Bosch (1991), pp. 39-55. 
A la luz de la fórmula norteamericana puede sostenerse que Dávila se anticipó e incluso fue más allá en lo que a la intervención del mercado, la acción estatal y el combate a la oligarquía (cuestión central en el ideario del Partido Socialista de Chile fundado en abril de 1933) se refiere ${ }^{52}$.

Mirada la cuestión desde otra perspectiva, la influencia del APRA en el socialismo chileno ${ }^{53}$, cabe rescatar el Plan de Acción Inmediata o Programa Mínimo que aprobó en 1931 el Primer Congreso Nacional del Partido Aprista (lanzada ya la candidatura presidencial de Haya de la Torre para las elecciones de octubre de 1931). Las medidas que se proponen implican un programa de Gobierno que supera la visión del Estado pasivo liberal, y tienen cierta semejanza con lo hecho por la República Socialista y por Dávila ${ }^{54}$.

Los meses de julio-septiembre de 1932 gestaron un Estado activo en materia socioeconómica, cuyas posibilidades de intervención en favor de las clases populares y capas medias dependerían del interés de las fuerzas políticas en juego.

Dávila describió su perspectiva de socialismo de Estado en junio de 1932:

"El Socialismo de Estado no significa violencia, injusticia, persecución; es un concepto total, científicamente contenido en la experiencia, en los hechos, y generoso porque conduce a la redención de los humildes (...) No significa despojo. No consiste en el empobrecimiento de una clase social para enriquecer a otra. El Socialismo planea una nueva economía que tiende a reintegrar en el mecanismo de la producción y el trabajo, las potencias sociales trituradas y deshechas por la vigencia de una economía liberal y anarquizante.

El Socialismo post-guerra habla de creación, producción, disciplina, autoridad y es la antítesis de este socialismo romántico nacido en el periodo embrionario del desarrollo industrial, versificador de la violencia y de la lucha de clases.

El Socialismo de Estado respeta las creencias y no persigue a las personas; destruye sí, y con energía, el interés que procure perturbar o impedir el desarrollo de su

52 Véase de LASKY (1980), pp. 190-210.

STEMPLowski (1980), pp. 333-342, señala en su trabajo que el embajador de Estados Unidos apoyó personalmente a Dávila.

53 De la que da noticia el trabajo de ReVeco Del Villar (1992), p. 395. A quien agradezco por el muy enriquecedor intercambio de ideas a propósito de este trabajo.

54 Juan Manuel Reveco del Villar nos comentó que se habla de un aprismo rooseveltiano. Entre 1945 y 1948 Haya de la Torre se mostró interesado en el New Deal, según da cuenta el artículo "Hacia la democracia aprista”, contenido en su libro ¿Y después de la guerra ¿qué? (1945): lo entiende como un caso de planificación económica en democracia sin sacrificar la libertad humana. 
acción. No satisface, como el régimen individualista, el egoísmo de los menos con la explotación de los más, ni estrecha en los círculos fanáticos y corrompidos la defensa de su doctrina" 55 .

No existe, por lo tanto, una diferencia insalvable entre lo hecho por Dávila y lo realizado por la República Socialista de junio de 1932, ni tampoco una fosa que separe el ideario de Grove y Dávila.

¿Cuál es el alcance de las expresiones Régimen socialista, Estado socialista en la etapa julio-octubre de 1932? Stemplowski, en sus distintos trabajos sobre la República Socialista y las ideas políticas de Carlos Dávila ${ }^{56}$, señala que éste tuvo plena conciencia de la necesidad de sustituir el régimen económico social. Le interesaba introducir la idea de la función social del capital y de la propiedad (según la visión de León Duguit), el término de la explotación de los pobres por los ricos y también atacar la anarquía de los elementos populares. Todo lo cual requería de un Estado jugando un rol activo en la economía, influyendo incluso en la producción y desarrollo de la actividad económica. Reflexionaba en este sentido que resultaba de interés tomar de las revoluciones del siglo XX, aquello que se mostraba útil para la situación de crisis que vivía Chile (tanto a nivel de capital como de trabajadores). Todo lo cual no fue obstáculo para reconocer ciertos elementos del liberalismo, tomados, dice Stemplowski, del mismo Adam Smith.

Para configurar la identidad de la acción y propuesta de Dávila, utiliza la expresión socialismo de Estado y también la noción parasocialismo estatal ${ }^{57}$. Afirma, por otra parte, que puede sostenerse con cierta credibilidad que la propuesta no tiene antecedente en el socialismo criollo y sí en la reflexión norteamericana y europea, en concreto en lo que se refiere a la función social de la propiedad y la actuación del Estado en contra de los grandes consorcios (cabe presumir, dice Stemplowski, que en Estados Unidos conoció la crítica social de Ward y de Colly).

Destaca un conjunto de elementos que le permiten sostener que el ideario y propuesta de Dávila es un fenómeno distinto de la República Socialista de Matte

55 Semanario Hoy, número 10 de junio de 1932, cit. por Castillo-Figueroa et al. (2005).

56 STEMPLOWSKi (1989), pp. 391-387.

57 Según se desprende de los antecedentes aportados en el capítulo VII de la obra ya citada de DevÉs y DíAz, la noción socialismo de Estado es empleada por algunos de los sectores que concurrieron a la fundación del Partido Socialista. 
y Grove, pero entiende que desde el punto de vista de sus medidas y acciones concretas, incluso desde el punto de vista de sus planes (Plan Lagarrigue ${ }^{58} \mathrm{y}$ Plan Dávila $\left.{ }^{59}\right)$, guardan cierta semejanza ${ }^{60}$. Engloba todas las experiencias bajo la expresión socialismo de Estado y rescata el carácter anticipatorio de las mismas ${ }^{61}$.

Respecto del uso de la voz socialismo, Devés y Díaz señalan:

"Hemos considerado en esta recopilación aquellos textos en que sus autores se definieron como 'socialistas', opuestos al capitalismo como sistema económico y al liberalismo como ideología. Pero este criterio general, se especificaba según los casos en oposición a las doctrinas demócratas o anarquistas, en relación a la Segunda o Tercera Internacional, o a la revolución del 17 y a la construcción del socialismo en la URSS"62.

Por otra parte, esta normativa irregular pone en tela de juicio la tesis de Gabriel Salazar sobre la contradicción insalvable entre las demandas de la soberanía popular constituyente y el entramado institucional creado por la clase política. Señala a este respecto:

"La propuesta legislativa central de la AOAN era la creación de una Junta Nacional de Subsistencias, un organismo de categoría estatal que debía abocarse a resolver los problemas económicos que incidían en las condiciones de vida de la población. Sin duda que eso implicaba añadir una prótesis social a un Estado (el de 1833) que precisamente jamás había desarrollado políticas productivistas y de justicia social" 63 .

58 El Plan puede consultarse en Devés y Díaz (1987), pp. 191 y ss.

59 El autor llama Plan Dávila al artículo "Chile no está arruinado", que éste publicó el 5 de mayo de 1932 en los diarios Crónica y La Opinión, y que fue reeditado como folleto en agosto de 1932, bajo el título "El Presidente Dávila y la Revolución de Junio” y denominado desde entonces como Plan Dávila.

60 Varias de estas ideas aparecen reiteradas en STEMPLOWSKI (2013), pp. 420-412: "El estado tenía su autonomía. No era la propiedad de una clase o un grupo, no era un comité de gestión de la clase propietaria. En esas condiciones el socialismo de estado constituyó a su manera una continuación y el final de las reformas iniciadas en los años 1924-1925, también con la participación del ejército... la República Socialista ha preparado el camino para la coexistencia del movimiento socialista con el estado capitalista -como lo hubiera deseado Vollmar, atenuando el conflicto de clases y como lo hubiera dicho Kautsky, enseñando la dirección de la reorganización del estado capitalista”. Agradezco a Magdalena Majda la traducción.

61 STEMPLOWSKi (1989), pp. 81-96.

62 Devés y Díaz (1987), p. 15.

63 Salazar (2009), p. 48. 
Lo hecho por Dávila en tan breve tiempo, implicó la gestación de un entramado institucional que se hizo cargo, bajo las voces de Gobierno y Estado socialista, de dichas demandas superándolas incluso.

Carlos Dávila sostuvo en 1956, 24 años después de su experiencia de 1932:

"El liberalismo extremo y el marxismo extremo, aunque son filosofías que se excluyen mutuamente, tienen sin embargo, mucho en común. Ambas son inhumanas y, en realidad no tienen fe en la inteligencia humana ni confianza en la capacidad del hombre para sobreponerse a las leyes económicas o humanizarlas, tal como lo está logrando con las leyes de la naturaleza.

En último análisis, eso es lo que las dos filosofías tienen en común: el determinismo.

En el hecho, ni el marxismo ni el spencerismo han probado todavía sus postulados en la práctica. El marxismo aplicado se encuentra aún en etapa experimental. El capitalismo por su parte no se ha hundido, aunque tampoco ha producido lo mejor para los más. Durante dos siglos de apogeo capitalista, dos terceras partes de la humanidad han continuado viviendo en la miseria y la desesperanza" 64 .

\section{CONClusiones}

Carlos Dávila adoptó en el período junio-septiembre de 1932, por vía de legislación irregular, un conjunto de medidas destinadas a la transformación del Estado liberal clásico chileno, empleando como elemento legitimador de dichas reformas las voces Estado socialista, Gobierno socialista, Régimen socialista, Programa socialista de Gobierno, Régimen de Gobierno socialista, República Socialista, leyes y doctrina socialista. Voces que sirvieron para configurar la identidad de un nuevo estado de cosas caracterizado por la intervención estatal de la economía, el combate a la especulación y la usura, el establecimiento de campos vedados para el lucro (como la seguridad social), y la creación de una institucionalidad estatal para avanzar en la solución de los problemas del mundo del trabajo y de los pequeños productores y comerciantes, mediante el despliegue de acciones estatales.

Dicha normativa jurídica tiene un mayor volumen que la del gobierno denominado República Socialista, tanto en términos de legislación promulgada como en lo relativo a las disposiciones normativas. De hecho, la dinámica jurídica de

64 DÁvila (1956), p. 147. 
los gobiernos de Dávila permite su vinculación con el Gobierno de la Unidad Popular a través del Decreto Ley No 520 de 1932.

Los actores que protagonizan esta transformación, entre otros Grove y Dávila, no parecen estar distanciados de las demandas de los sectores populares y medios en la coyuntura de la gestación de la Constitución de 1925. La actividad legislativa desplegada a partir de 1932 procuró dar satisfacción en medida relevante a dichas demandas.

Los actos de la República Socialista y de los Gobiernos que le sucedieron, que se ocuparon según su discurso oficial en construir el Estado Socialista, parecen ser una respuesta a la interrogante planteada por Navarro López:

"Cabe preguntarse aquí por el real alcance de este proyecto constitucional popular. Para nuestro argumento, la alta abstención del plebiscito constitucional confirma el importante alcance del proyecto popular en desmedro del autocrático proyecto alessandrista. Pero aún así ¿qué proyecciones tuvo el proyecto constitucional popular dentro de las luchas populares que siguieron a la coyuntura del '25? ¿Cuán lejos llegó el impulso de sentir la necesidad de crear una Constitución Política que representara 'al elemento mayoritario de la nación’? ¿Dónde se pierde el rastro de esta iniciativa?”65.

El socialismo de Estado de Dávila, la idea de una función social de la propiedad y de un Estado activo, constituyen una modalidad de ejercicio del poder distinto de la propia del Estado Liberal. Dávila invocando el socialismo, anticipó por vía legislativa y no constitucional, lo que podía hacerse en favor de las clases más desposeídas por un Estado activo que no desahuciaba la propiedad privada, la democracia ni las libertades.

Desde el punto de vista de la práctica política (construcción de un entramado de instituciones estatales), no del discurso doctrinario, carece de sentido una comprensión de los liderazgos de Grove y Dávila en términos de oposición o dicotomía. A los ojos de un socialista connotado como Grove, lo hecho por Roosevelt era lo apropiado en la medida que implicaba un combate a la oligarquía, es decir, el Estado activo era parte del camino a recorrer para llegar al socialismo. Para el caso chileno, Dávila asfaltó dicho camino y lo proyectó aun antes que los norteamericanos (enfrentando una coyuntura más o menos semejante).

Para los defensores del Estado liberal clásico, esta visión de un Estado que atiende activamente intereses pluriclasistas reúne características suficientes para ser calificado como Estado socialista. Dávila y sus medidas dejaron en manos de

65 NaVArro (2009), p. 15. 
los defensores del capitalismo una suerte de Estado Socialista avant la letre: aun sin la implementación de una economía centralmente planificada consagrada constitucionalmente, un Estado, un Gobierno puede ser calificado de socialista en la medida que su accionar limita el despliegue de la iniciativa privada y establece campos vedados para la empresa y el lucro. Según esta visión, basta con intervenir el mercado y configurar un entramado estatal al servicio de las clases subalternas, para configurar un Estado de tipo socialista. En este sentido el accionar de Dávila, tanto o más que el de la denominada República Socialista, vino a dotar de contenido fáctico a las voces programa socialista del Gobierno, régimen de Gobierno socialista, Estado Socialista y régimen socialista a los ojos de la oligarquía chilena.

\section{BiBLIOGRAFÍA CITADA}

\section{Libros y artículos consultados}

Aylwin, Mariana; Bascuñán, Carlos; Correa, Sofía: Gazmuri, Cristian; SerraNO, Sol; Tagle, Matías (1992): Chile en el siglo XX, 4a Edición (Santiago, Editorial Planeta).

Arrate, Jorge y Rojas, Eduardo (2003): Memoria de la Izquierda Chilena (18501970), (Santiago, Ediciones B. Chile S.A.), Tomo I.

Bosch, Aurora (1991): "Estados Unidos en los años treinta: ¿Un socialismo imposible?”, en Historia Social (No 11), pp. 39-55.

BüCHI Buc, Hernán (1993): La transformación económica de Chile. Del estatismo a la libertad económica (Colombia, Editorial Norma S.A.).

Casanueva Valencia, Fernando y Fernández Canque, Manuel (1973): El Partido Socialista y la lucha de clases en Chile (Chile, Empresa Editora Nacional Quimantú).

Castillo Medrano, Andrés; Figueroa Román, Arturo; Freire Vallejos, Matías; IbÁNez BALlesteros, Rodrigo (2005): Los cien días de Dávila: la política económica del "Socialismo de Estado" (Tesis de Licenciatura en Historia, Universidad de Chile) [Disponible en: http://repositorio.uchile.cl/tesis/uchile/2005/ castillo_a/html/index-frames.html].

Corvalán M., Luis (2015): "Identidad, ideología y política en el Movimiento Nacional Socialista de Chile 1932-1938", en Revista Izquierdas (No 25), pp. 76-119.

Cruz Salas, Luis (2002): La República Socialista de 1932, (Santiago, Ediciones Tierra Mía). 
DÁvila, Carlos (1956): Nosotros los de las Américas (Santiago, Editorial del Pacífico S.A.).

Devés, Eduardo y Díaz, Carlos (1987): El pensamiento político en Chile. Antología 1893-1932 (Santiago, Documentas Ediciones).

Dinamarca, Manuel (1987): La República Socialista Chilena. Orígenes Legitimos del Partido Socialista (Santiago, Documentas Ediciones).

Drake, Paul W. (2004): "La misión Kemmerer a Chile: consejeros norteamericanos, estabilización y endeudamiento, 1925-1932", en Revista de Estudios Históricos (Volumen 1, No 1).

Jobet, Julio César (1987): Historia del Partido Socialista de Chile, 2a Edición (Santiago, Ediciones Documentas/Estudio).

Jobet, Julio César (2015): "Revolución socialista de 4 de junio de 1932", en Arauco número 8, 1960, en José Balaguer, editor, Obras Completas de Julio César Jobet, Volumen I (Santiago, Ediciones de la Biblioteca Clodomiro Almeyda Partido Socialista de Chile).

Jobet, Julio César (1971): El Partido Socialista de Chile. Tomo I (Santiago, Ediciones Prensa Latinoamericana S.A.).

LASKY, Harold J. (1934): “El Experimento de Roosevelt", en El Trimestre Económico (Vol. 1, No 2), pp. 190-210.

LOVEMAN, Brian y LiRA, Elizabeth (2000): Las ardientes cenizas del olvido; vía chilena de reconciliación política 1932-1994 (Editorial LOM, Dibam).

NAVARro López, Jorge (2009): "Experiencia popular acumulada en la coyuntura constitucional de 1925", en Izquierdas (número 4, año 3), pp. 1-17.

Novoa Monreal, Eduardo (1970-1971): "Vías legales para avanzar hacia el socialismo", en Revista de Derecho Económico (año IX, números 33 y 34), pp. 26-38.

Pellegrini Ripamonti, Elisa (1988): La República socialista de 1932 (Tesis de Licenciatura, Pontificia Universidad Católica de Chile), p. 116.

Reveco del Villar, Juan Manuel (1992): "Influencia del APRA en el Partido Socialista de Chile", en Juan Manuel Reveco et al., Juan Manuel Reveco del Villar, Vida y Obra de Víctor Raúl Haya de la Torre, Cambio y Desarrollo. (Perú, Instituto de Investigaciones), p. 395.

Saenger Gianoni, Fernando (2003): "Veinte años de recurso de inaplicabilidad por inconstitucionalidad", Anuario Iberoamericano de Justicia Constitucional (número 7), pp. 401, 462.

Simonetti de Groote, Susana (1995): "El Gobierno de Carlos Dávila 16 de junio-13 de septiembre de 1932", en Boletín de la Academia Chilena de la Historia (año LXII, número 105), pp. 293-360. 
STEMPLOWSKI, Ryszard (1988): "La diplomacia alemana frente a la República Socialista de Chile de 1932", en Jahrbuch für Geschichte Lateinamerikas, Anuario de Historia de América Latina (JbLA), (No 25).

STEMPlowski, Ryszard (1978): "Chile y las compañías petroleras, 1932-1932. Contribución al estudio del entrelazamiento dominación-dependencia”, en Ibero-Amerikanisches Archiv N.F. (Jg 4 H.1.).

STEMPLOWsKI, Ryszard (1980): "La República Socialista de Chile de 1932 vista por el Foreign Office. (Una reconstrucción de la imagen, basada en materiales del Public Record Office)", en Estudios Latinoamericanos 6 (Vol. II), pp. 333-342.

STEMPlowski, Ryszard (1989): "Hacia la autonomización y totalización del Estado: Carlos Dávila y su concepción del socialismo de Estado", en Academia de Ciencias de Polonia, pp. 361-387.

STEMPLOwsKi, Ryszard (2013): "Panstwowy socjalizm w realnym kapitalizmie. Chilijska reakcja na swiatowy kryzys gospodarczy" (1932 r.), (Warszawa, Biblioteka Iberyjska).

STEMPLOWsKi, Ryszard (1989): "Las Antinomias políticas chilenas de la libertad. Las experiencias de la época de la Gran Depresión y su relevancia contemporánea”, en Acta Poloniae Historica (LX), pp. 81-96.

SulE, Anselmo (1980): "El avance hacia el socialismo. La experiencia del Gobierno de la UP en Chile", en Nueva Sociedad (número 46), pp. 101-109.

Yopo, Boris (1984): "Estados Unidos y el Partido Socialista Chileno 1933-1946: un estudio de percepciones politicas" (Tesis para optar al grado de Magíster en Estudios Constitucionales, Instituto de Estudios Internacionales, Universidad de Chile).

Salazar V., Gabriel (2009): Del poder constituyente de asalariados e intelectuales (Chile, siglos XX y XXI), (Santiago, Editorial LOM Colección Historia).

\section{FUENTES DIRECTAS}

Contraloría General de la República. (1933) Recopilación de los decretos-leyes dictados en 1932, por orden numérico, con índices por número, Ministerios y materias. (Santiago, Imprenta Nascimento).

Informe Jurídico de la Comisión nombrada por el Supremo Gobierno para el Estudio de los Decretos Leyes y Decretos con Fuerza de Ley (1933), Santiago de Chile, Editorial Progreso. [Disponible en: http://www.memoriachilena. $\mathrm{cl} / 602 / \mathrm{w} 3$-article-31403.html]. 